\title{
Students' Perception of Different Learning Options and Use of Authentic Research Papers in a First Year Engineering Course
}

\author{
http://dx.doi.org/10.3991/ijep.v5i4.4923 \\ B. Schmidt \\ Mads Clausen Institute, University of Southern Denmark, Sonderborg, Denmark
}

\begin{abstract}
This case study presents a teaching strategy for an engineering dynamics course using a range of different learning options supporting different learning styles. The teaching strategy was implemented in a blended learning environment by combining traditional lectures with online resources. Additionally, hand-in assignments based on authentic research papers were introduced. Two sets of questionnaires were given to evaluate the students' perception of the different learning options. The study shows that the students found online pencasts very useful as a means to increase the outcome of studying a traditional textbook. The implementation of an electronic audience response system to enhance active learning by peer instruction in combination with traditional lecturing was highly appreciated by the students. The students found it difficult and time consuming to work with real research papers but many students expressed that it was stimulating to see that the theory is used today by practitioners in engineering. Finally, the study indicates that the proposed teaching strategy as estimated by the students leads to increased motivation and engagement in their study.
\end{abstract}

Index Terms-Blended learning, learning styles, primary literature, students' satisfaction.

\section{INTRODUCTION}

Helping young students to become skilled and innovative engineers is not an easy task. One of many issues is how to transfer knowledge earned in a theoretical course into useful competencies when dealing with real engineering problems. The Faculty of Engineering at the University of Southern Denmark has tried to address this problem by assigning $1 / 3$ of the student's work load each semester to a specific semester project comparable to a real-life engineering problem. The idea is that the students learn how to use the theory discussed at the more traditional courses, thereby finding the theoretical courses relevant and in fact crucial for their education. In spite of all good intentions with these semester projects, it does not always work that ideal! For instance, when talking engineering dynamics, it is striking that while students might be good at solving text book exercises, this does not imply that they are able to use their knowledge in more realistic engineering problems that they encounter in a semester project [1]. As an attempt to overcome this challenge the teaching strategy in a theoretical course in fundamental engineering dynamics was changed by setting up a blended learning environment.
With the advancement of technology the use of blended (or hybrid) learning at university level has developed a lot over the last decade. This teaching strategy can be defined as 'a mix of several didactic methods and delivery formats' [2]. Moebs and Weibelzahl [3] advocate for blended learning being the integrated learning activities such as a mixture of online and face-to-face learning. In this context we will adopt to a type of blended learning where different traditional teaching styles are combined with different kinds of elearning - a definition that seems to be more often used in the literature [4].

The increased use of blended learning is a consequence of not only the progress in technology but also of the economic and political conditions for educational institutions and of the globalization in general. Many universities face a reality where they have to teach more students with fewer teachers [5]. Blended programs have been suggested as a way to increase cost-effectiveness in education, i.e. the learning outcome is maintained or even increased despite a reduction in teaching costs [6]. The increased access and flexibility offered in a blended learning environment enhances distance learning, too, and thereby gives a possibility to reach a larger student volume with a positive influence on cost-effectiveness as a result.

On the other hand there is a range of reasons of more pedagogical nature, why blended learning by some authors have been proposed even as the ideal teaching concept for the future $[7,8]$. This is due to the fact that as student population growths the teachers find themselves with an impossible task: to choose the optimum teaching style for the students. Even if all the relevant teaching styles are known, it is not possible to implement all these teaching styles simultaneously at class to meet the students' needs [9]. Students who have different needs, different background levels of knowledge and different learning styles are equally not satisfied with traditional teaching and learning environments [10]. Implementation of blended learning is seen as a promising strategy to address this problem, since it allows integration of traditional learning with web-based or computer-based learning tools and combinations of a number of pedagogical approaches [11]. As pointed out by Peercy and Cramer [5], successful blended learning cannot be a mish-mash of traditional lecturing with some online content but needs to involve a thoughtful redesign course pedagogy implying meaningful new interactions with students. 
Another way to try to link the course work in a theoretical course to the more practical work in a semester project could be to incorporate authentic research papers related to the task in the semester project. Tertiary literature like textbooks seems to play the main part in empirical and applied science studies, especially during the first semesters. This is for obvious reasons since most textbooks are well-written, provides an overview of the topic and are often revised several times. Some might even present a glance into the research process through extracts or mentions of research papers or interviews with esteemed researchers [12]. As opposed to textbooks the primary literature like peer-reviewed papers represents the academic "gold" in the applied sciences. They are concise and with a strong academic focus. They are in general well-written because of the review process and some illustrate directly how a scientist works. These features of an authentic research paper could make it a useful supplement to more traditional teaching materials as long as the obvious difficulties with very specialized theories, esoteric terminology, advanced methods etc. can be dealt with.

This paper reports how a blended learning structure was established in a second semester engineering dynamics course. Special emphasis was put on facilitating several learning styles and on increasing the learning output by stimulating active learning. At the end of the semester a survey was carried out in order to measure the students' perception of the efficiency of the different learning options as a first indication of the strength of the proposed learning environment. In addition it was possible to track the number of students viewing the online materials and in this way getting data on the use of these materials. In addition, the students were presented for three recent, authentic peer-reviewed papers dealing with topics with clear relation to the semester project theme. These papers were used as the framework for three mandatory written assignments that the students had to do individually. The aim of the study was to seek an answer to the question whether first year engineering students can benefit from reading peer-reviewed papers while the learning goal of the assignments was a threefold:

a. to increase the motivation for the theoretical course by showing that the topics are (still) used in actual research.

b. to inspire the students' work in the semester project.

c. to illustrate how research results are presented by professionals.

Hence, in the model of research informed teaching by Healey [13] the use of the research papers constituted research-led as well as research-oriented teaching since the students not only learned about current research in the discipline but also developed research and enquiry skills and techniques by putting an emphasis on research processes and problems.

\section{RELATED WORK}

When designing a course structure to benefit from blended learning it is important to strive for the blend to involve the strengths of each type of learning environment and none of the weaknesses. Osguthorpe and Graham [14] have identified six general goals to aim for in this context: (1) pedagogical richness, (2) access to knowledge, (3) social interactions, (4) personal agency (learner control), (5) cost effectiveness, (6) ease of revision. It is crucial to consider how or to what extend these goals can be achieved when blended learning is implemented into a course design.

In engineering educational research quite some work on how to use a blended learning strategy has been published, but not particularly in engineering dynamics. Boyle [15] shows how such a strategy used in an introductory programming course can address a common problem dealing with the abstract nature of certain programming concepts. Here a development of multimedia learning objects enabled the students to engage visually with these concepts and hence overcome the problem of abstraction. Another study on a blended learning approach in a computer programming course for first year engineering students indicate that online tools can be very beneficial for the students, and it improves the student satisfaction with the course [16]. Groen and Carmody [17] found that in teaching first year engineering mathematics the blend more closely mirrors the professional practice and is more likely to encourage a deep approach to learning. The majority of the students responded favorably to the blend. Similar results on positive student feedback and especially regarding improved student motivation in engineering mathematics has been reported by Wan Ahmad et al. [18]. A particular interesting approach to design a mathematics course within a blended learning framework has been suggested by Markvorsen and Schmidt [19]. They consider the technology enhanced learning of first year engineering mathematics and especially the application of different elearning objects and principles. Because of a yearly intake of 750 students at this course, it has been possible to allocate a significant amount of resources into producing introductory videos, interactive web-based tutorials, online textbook materials, pencasts, and podcasts of the lectures etc. Even though the effect of their non-linear multimedia technology and e-learning principles is not yet fully analyzed, they can report that it strengthens and enhances the students' desire and ability to prepare for teaching, and they have received positive response from the students regarding the facilitation of different learning styles.

In engineering education it has been explained that elearning in general is most effective when used as a supplement to more traditional strategies rather than a replacement for them [20]. In fact, traditionally the science- and mathematics-based engineering courses are the hardest to teach online because of the need for laboratories and equation manipulation [21]. Newer research shows that to improve the success of blended learning the teacher should adopt strategies that promote not only teacher-student interactions but also enhances class attendance, student-student interactions and motivation [22]. These findings agree with a study on students' perspectives on learning in a blended environment [10], where students stated that their learning output could be improved by using a more interactive teaching approach with the use of collaboration tools and receiving individual feedback. A method to facilitate a more interactive learning frame is to include peer-instruction in the classroom. This teaching style has been found to be very efficient also in a mathematics-based topic as dynamics and in physics in general [23]. Peer-instruction can be enhanced by 
introducing an electronic audience response system like 'clickers' in the teaching [24, 25]. Some results on students' satisfaction with clicker-induced learning in engineering dynamics has been reported by Fang [26], who found that students appreciate this teaching approach and the exam performance seemed to be enhanced, too. Another study on peer instruction supported by clickers in an engineering dynamics course revealed that it led to an increased learning output, especially regarding the students' conceptual understanding of the subject. Furthermore, the data showed the students to be very satisfied with this teaching style and they gave high rankings on several parameters, which are important to the learning process [27].

Hence, there is a wide range of learning options that can be facilitated in a blended learning environment. However, it is important to keep in mind that the course structure should be very transparent to the students in order to help the students managing their time in such environments and maintaining their self-motivation [28]. Since the development of a range of learning options is a resource demanding process, this will usually be a limiting factor, and especially for smaller classes. This was very much the case for the course considered in this paper.

Considering the use of authentic research papers in first year university teaching the literature seems to be rather scarce. A few examples from life sciences can be found $[29,30]$ with a focus on presenting the academic genre with respect to metacommunication, application of theory, presentation of results and discussion but in fact the latter reference deals with a fictious paper to illustrate these points. Bean [31] finds that first year undergraduate students are able to read peer-reviewed papers without "rhetorical sophistication", though. Another relevant study where the students were asked to work with an authentic paper during the first week at university has been published recently [32]. In this study the peerreviewed paper deals with a quite general and transparent issue of mobile phones and why they are annoying when used in public areas [33]. Hence again the main purpose is to expose the students to the IMRD-format of a scientific paper (Introduction, Methods, Results, Discussion) and not to combine with the actual topic of the program which in that case was computer programming.

\section{BLENDED STRUCTURE IN AN ENGINEERING DYNAMICS COURSE}

\section{A. Course Setup}

The course studied was a second semester engineering dynamics course. Topics were dynamics of rigid bodies and it was a follow-up on an introductory course on particle dynamics at the first semester.

A total number of 56 students from three different engineering programs were enrolled at the course. By the study administration the students were divided into two classes because of the use of two teaching languages (Table I). Both classes were taught by use of the same blended learning approach and by the same teacher, hence in this work all 56 students are treated as belonging to just one sample. Lectures of 90 minutes were given once a week to each class. The students were evaluated for their final grades at an oral examination.

\section{B. Learning Options and Ressources}

The following study materials were offered to the students. All materials were available online at the course web-page, except for the textbook.

Pencasts. A pencast is a computer file where a handwritten note is recorded along with the instructor's vocal explanations. This file can be watched by the student in real-time. One advantage is that the student can repeat difficult steps over and over and hear the instructor's explanations for exactly this part as many times as wanted. To each lecture a pencast of 6-9 minutes were developed telling about the main concepts of the week and how they were related to each other and to previous discussed concepts.

Lecture notes. These were hand-written pdf-files consisting of theory and examples for the week's topic. The purpose of the lecture notes was a two-fold: To prepare the student before reading the textbook and save time at the lectures because students did not have to take notes all the time.

Textbook. The textbook used was a standard engineering dynamics textbook by Meriam and Craige [34].

Voting tests. These tests consisted of six to nine multiple choice questions for each lecture. The questions were made to challenge the students' general understanding of the topic and their conceptual understanding in particular. At the lectures the students voted (by use of clickers) on the answers they found to be correct and the results were used to stimulate peerdiscussions. Mainly, the voting tests were uploaded in order to give the students the possibility of working with the test questions not only at class but after class, too.

Hints and answers. To each lecture a number of exercises were recommended for individual study or group work. To encourage students to work on these exercises a file with hints and answers were uploaded to the web-page each week.

Discussion boards. The students had to hand-in three individual assignments during the course and to each of the assignments a discussion board was created in order to facilitate student-to-student interactions regarding this work.

Other materials. Occasionally, the students were given links to existing online materials, youtube clips, etc. and online materials suggested by the students were distributed on the web-page, too.

\section{Suggested learning strategy}

At the beginning of the course the students were carefully presented for the range of learning options.

TABLE I.

DEMOGRAPHIC DATA

\begin{tabular}{|c|c|c|}
\hline Language & Engineering programs & $\begin{array}{c}\text { Number of } \\
\text { students }\end{array}$ \\
\hline English class & $\begin{array}{c}\text { Mechatronics } \\
\text { Innovation \& Business } \\
\text { Interaction Design }\end{array}$ & 42 \\
\hline Danish class & Mechatronics & 14 \\
\hline
\end{tabular}


They were recommended to start up applying the learning strategy sketched in Fig. 1 as this was seen as a strategy that probably would suit a majority of students.

As shown in Fig. 1 the students were suggested to start a new topic by watching the pencast. This should prepare them to achieve a better outcome when studying the textbook before attending class. The lecture notes were supposed to help the students with this task, too.

Hence, when students met in the classroom, they had already studied the subject and gone through some sample problems in the textbook. For this reason, the teacher gave only a short presentation to cover the most important parts of the topic (typically 10-15 minutes).

Then the voting test was carried out. After presenting a question on the screen, the students were asked to answer the question on their own and give in their answer anonymously through a clicker handed out to each student at the beginning of the lecture. Automatically, the distribution of given answers were shown on the screen to motivate the students for the following peer-discussion. After some minutes of discussions, the students were asked to vote again on the same question. Normally, the second voting showed much better agreement as a result of the peer-discussions. A concise conclusion to the question was stated by either one of the students or the teacher. Usually, this voting-session took up 30-40 minutes. The remaining part of the lecture was held in a more traditional form with focus on working out examples and problems, some of them covered by the lecture notes and some not in order to give possibility to have class-discussions on different problem solving strategies. Occasionally, experiments were carried out at class to demonstrate specific concepts and to relate to real world examples.

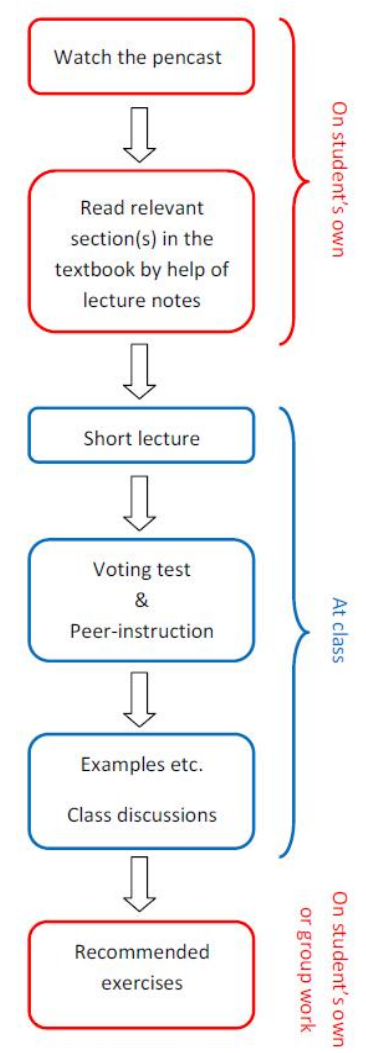

Figure 1. Suggested blended strategy.
The students were urged to work on the recommended exercises after class, either on their own or in study groups. If they were able to solve these exercises the students could see this as an indication of him or her mastering the topic!

\section{Use of authentic research papers}

This part of the study was carried out in the same course but at a later year where the blended teaching strategy had found a stable form. A total of 70 students were enrolled this year covering the same three engineering programs and taught in two classes. Three quite new and authentic research papers were presented at the first day of the semester as a kind of 'appetizer' regarding what kind of engineering problems makes use of the dynamics treated in the course. The first paper discusses the optimal control of a half-circular compliant legged monopod [35] and the second studies the effect of toe stiffness on ankle kinetics in a robotic prosthesis [36]. They were both chosen because of a clear IMRD-structure and because they aligned nicely with most of the students building a robot with a specified task in the semester project. The third research paper compares the tail-assisted pitch control in lizards, robots and dinosaurs and was published as a letter in Nature a few years ago [37]. Hence this paper does not follow the normal IMRD-format, but was chosen merely because of its relevance for the students' semester projects and for the stimulating and intriguing topic.

The research papers constituted the material for three mandatory assignments for the students to hand in individually during the semester. The first and second assignment had a very similar frame work. First, the student should write a new abstract with focus on what was especially relevant in that particular paper for their own project work. This approach is in alignment with the method of using writing as a tool for creating deeper thinking [38]. Next, the student should explain how the dynamic model in the paper could be established from the concepts and formulas established in the theoretical course. Finally, there was an extra task with doing a bit more calculations for instance to check a certain value given in the paper or comparing a simple first year approximation with the result of the more complex modelling in the paper. The third assignment had a somewhat different focus and did not include writing a new abstract. Instead the student was asked to analyze the model established in the paper in more detail and do further calculations. The assignments were handed-in and the students received written feedback individually on their problem solving skills and presentation of the solution methods.

\section{Data Collection}

\section{A. Different Learning Options}

In order to collect information on how the students used the different learning options and how beneficial they found them, the students filled out an online questionnaire at the end of the course.

For each learning option the students were asked two questions:

(1) How often did you use the [learning option]?

(2) When you used [learning option] how effective (learning outcome per minute you spend) did you find it? 
Answers were given on a 5 point likert-scale $(1=$ 'Never'/'Not effective at all' to $5=$ 'Every week'/ 'Extremely effective' for question (1) and (2), respectively).

In addition the students were given the opportunity to answer two essay questions: One regarding the student's explanation on why some learning methods work well for him or her, and another one where the student should explain why some learning methods do not work for him or her.

Data from the questionnaire was gathered electronically and thus answers were given in fully anonymity. A total number of 50 students responded to the questionnaire (corresponding to $89 \%$ ). The amount of qualitative data from the essay questions was quite significant since 45 students (90\% of the respondents) gave input through this channel.

Finally, the number of students viewing the online materials was tracked as a means to monitor to which extend the different materials were used and also to track when they were accessed.

\section{B. Use of Authentic Research Papers}

When the papers were presented at the first day of the semester the students were asked to estimate their own amount of motivation for the course on a 5-point likertscale $(1=$ 'Not motivated' and $5=$ 'Very motivated' $)$. The students gave in their estimation electronically and anonymously, but only one of the classes was asked to do this. All 30 students present that day participated.

By the end of the semester all students enrolled had the opportunity to answer another anonymous survey with three questions concerning how motivating, relevant and difficult the student found the assignment based on the research papers. A fourth question dealt with the preferred kind of hand in assignment and finally the students could give in any comments via an open essay question. This questionnaire was answered by 38 of the students $(54 \%)$ while 17 students gave in some kind of general comment corresponding to $55 \%$ of the respondents and $24 \%$ of the total cohort.

\section{RESUlts}

Fig. 2 shows the average scores for the different learning options regarding how much the different materials have been used as well as the students' perception of the efficiency. In general it shows that the students gave the highest ranking to the activities that took place at the lectures (presentation of theory, voting tests/peer-discussions and examples). Reading lecture notes and watching pencasts are considered quite beneficial too, while the use of the voting test questions outside of classes, discussions boards and 'other materials' are found to be more rarely used and with poorer efficiency.

Even though not documented here, when comparing the scores on the use of the different materials given by the students and the tracking of the number of views they seem to agree well. Hence, the results on the use shown in Fig. 2 are considered quite reliable. Regarding the data on efficiency, being of a more subjective nature, it is unfortunately not possible to make any kind of comparison in order to validate the data.
As an example of the kind of data received from tracking the number of students viewing the online materials, the student views of the pencasts during the semester is shown in Fig. 3.

Results from the essay question and from the questionnaire regarding the use of authentic research papers will be part of the discussion in the following section.

\section{DISCUSSION}

\section{A. Learning Options before Class}

There were three main learning options for the students to work with before class: pencasts, lecture notes and the textbook. Fig. 2 gives a very clear indication that while the pencasts and the lecture notes were found to be very useful and efficient, the textbook was found to be one of the learning options with poorest efficiency of them all. Presumably for this reason, the students did not use the book very often.

This view on textbook and lecture notes reading was stressed by students' comments in the essay answers:

'Reading in books is just naturally so slow and boring.'

'Personally, I can't learn properly in a book. Some texts are too strange and difficult to read.'

'I read every week the lecture notes - they are really good because they have a nice overview and structure.'

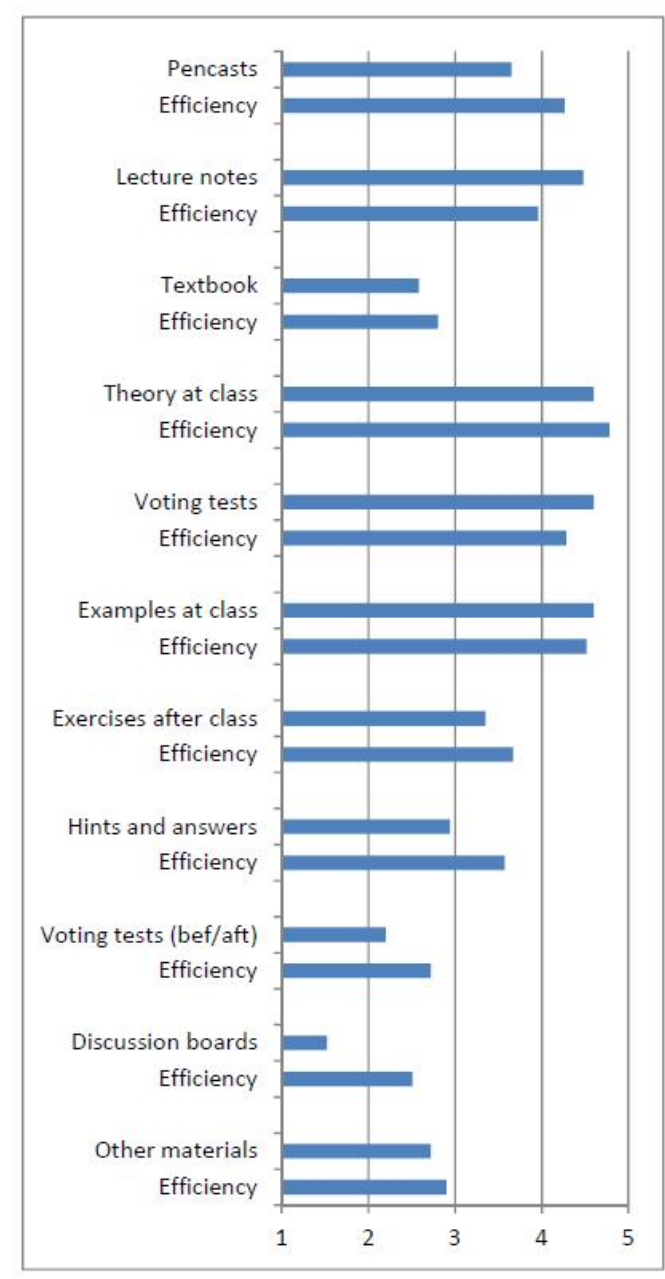

Figure 2. Average scores on use and efficiency. 
PAPER

Students' Perception of Different LeARning Options And Use of Authentic Research PAPERS IN A First...

The online lecture notes were found to be very popular among the students. This can be explained, at least partly, by the lecture notes being much easier read compared to the textbook. It is important though, in order to create the optimal learning, that focus is put on the lecture notes being a tool helping the students to benefit from studying the textbook rather than being an alternative to the book.

A study by Fitzpatrick et al. [39] indicates that students regard a good set of notes a requirement for a well-taught module, but in general the students are not convinced that this is sufficient. Hence, providing such lecture notes is not seen as an alternative to the textbook in this context. Since most careers in engineering in the future will be based on life-long learning, it is crucial that the students are provided with the skill to benefit from reading a traditional textbook.

Next to lecture notes specially produced video films have been suggested to help to prepare students for studying a textbook [19]. Since video production is a rather expensive solution, in this work it was chosen to make use of the pencast technology. Easily and inexpensively created with a digital pen with a build-in audio recorder, pencasts are very useful not at least for a course topic of mathematical nature. The pencasts made for this course was meant as 'appetizers' before reading the textbook but also to achieve direct learning, mainly in the sense of creating an overview of the subject. Fig. 2 shows that the students found the pencasts very efficient.

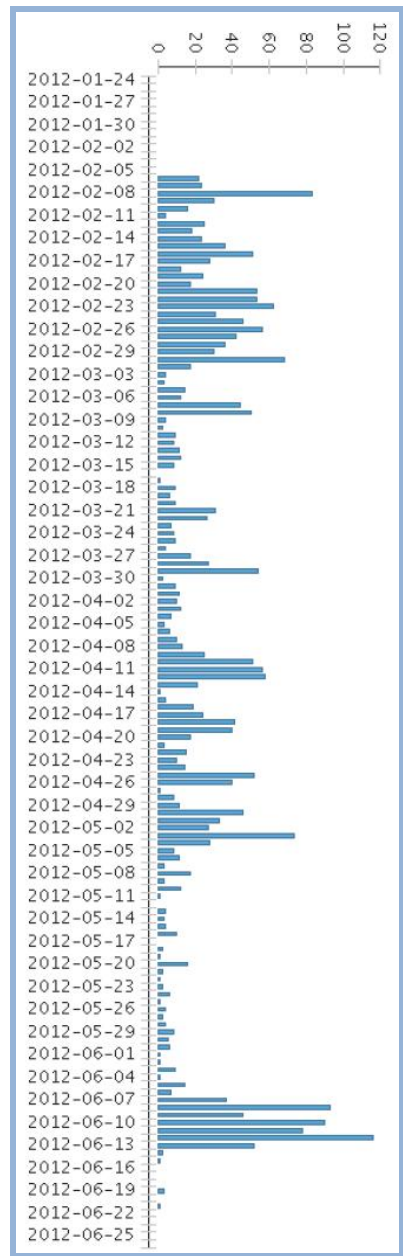

Figure 3. Number of student views of the pencasts during the semester. (Data from the English class).
Some students' comments on pencasts were:

'The pencasts are very great. They are short and precise - and the best thing: you can repeat every explanation until you've got it all!'

'Pencasts were new to me. It's a cool idea.'

'Pencasts work well for me because of the "listen-to-anywhereanytime" function. Repeat. Repeat. Repeat!'

In addition, the pencasts might also enhance the students' motivation to read the textbook:

'The pencasts I also think was a good idea to help me kick start on new theory and made reading the book easier.'

A similar observation has been made for video introductions [19].

An unexpected use of the pencasts can be deduced from Fig. 3 exploiting the number of students' views on the pencasts during the semester. Right from the beginning of the semester, the pencasts had quite a lot of hits. The decrease in students' views in a part of March was due to cancellation of lectures and a spring break. When the teaching period ended in the beginning of May the students did not access the pencasts very much anymore, but approximately one week before examination (starting June 12) there was a lot of activity again. Hence, even though the pencasts were made in order to be an option to be used before reading the textbook, the students used them quite a lot in preparation for examination.

\section{B. Learning Options at Class}

All three main elements when the students met at class: the teacher going through theory, voting tests and discussion of examples received high scores in efficiency, well above 4 on the 5-point scale. That a majority of students finds the teacher lecturing beneficial to their learning is in accordance with [39], which conclude that students require lectures as well. A lot of effort was put in to lecture on theory and applications in close connection to what the students had seen in the pencasts, in the lecture notes and in the textbook, but always so that the lectures added something new, a new idea, a new point of view etc. to give a further perspective to the subject. According to [39] these are very important factors regarding the students' perception of the efficiency of a lecture. This was supported by students' comments in the present study:

'I think the exercises we did in class and the explanations are very good. I like to work with examples. Then it is easier to remember.'

'Lectures and exercises at class build well upon the lecture notes as they both teach and challenge students. Personally, I appreciate the teaching style because it shows me how to visualize and approach physics problems effectively without tiring me by overloading me with grey theory that has long lost connection to the "real" world. The classes help me to apply theory flexibly with a fair understanding of what is actually going on.'

The voting test sessions at class were considered very efficient by the students, too. Previous work [27] has shown that using clickers to stimulate peer instruction can improve the learning outcome and student satisfaction in courses like engineering dynamics. In addition, the present case study indicates that the students themselves assess the efficiency to be quite high. Comments from the students on the voting tests gave credit to this teaching style to enhance satisfaction and motivation as well as to 
expose students' insight into the core of the learning process:

'Voting tests have satisfied me tremendously as they put the learned theory to test right away and helped me widening the view of physical implication around us.'

'Voting tests inspire students to use each other's knowledge of a given subject, and sometimes their way of seeing a problem differs from the teacher's.'

Facilitating peer instruction is one way to engage the students at class and stimulating active learning. To actively involve the students in the classroom is an important parameter to improve the lecture according to students' opinions [39]. Findings in the present study indicate that implementing voting tests and peer instruction at class should be considered a recommendable teaching style. In general, the essay answers from students show that the blended environment was quite appreciated by the students:

'Good mix of learning strategies can be the most useful way to learn new things and understand them!'

\section{Learning Options after Class}

Following the suggested learning strategy the main activity for the students after class was to work on the recommended exercises, either on their own or in study groups if preferred. As experienced by the teacher during the semester, the vast majority of students did work on these exercises and this work was seen as important by the students. To the students' disposal, in order to stimulate their work on problem solving, the web-page offered some hints and answers to all these exercises, but the questionnaire reveals that these materials were not accessed very much with an average score of approximately 3 (corresponding to the answer 'now and then'). Some students stated that they learned more from discussing and helping each other than from consulting the 'hints and answers' since they were found to be either too much or too poor. Some student comments indicated that it could improve this learning option if it could be given a more interactive form:

'The hints the teacher gave for the exercises could be more like, one hint, second hint, third hint and then if you can't solve it, use the forum...

A similar result seems to be the case for the 'discussion forum' established for each of three mandatory assignments. The discussion forums were not used very much, and since the benefits in a discussion forum totally depends on the input from the users the forums were not perceived efficient either. Even though the use of discussion forums has been reported very useful in teaching engineering [40] it was not the case in the course structure described here. Most likely, the reason was that the student volume was too small to create a real need for a discussion forum because most of the students met at different classes every day anyway.

\section{Use of Authentic Research Papers}

When the students were asked to estimate their motivation for the dynamics course first day at class the average level of motivation on the likert-scale increased from 4.1 to 4.7 by introducing the three authentic research papers. This spontaneous reaction is not surprising since a lot of students ask for applications for what they learn, especially in theoretical and introductory courses. Engineering dynamics is considered a vertically constructed discipline since the necessary mathematics and physics have a pronounced hierarchical structure [41]. Generally, at bachelor level it is hard to read primary literature in such a discipline and the students are well aware of this. Hence, when they are told that they will be able to work with these scientific papers very soon it is triggering a lot of these first year students.

By the end of the course the students found that the hand-in assignments based on authentic papers increased motivation still. A similar effect has been reported by [32] also. The questionnaire showed that 39\% agreed and $26 \%$ strongly agreed to the statement that these assignments were more motivating compared to traditional textbook exercises. The link to real life applications is appreciated in several student comments:

'It's nice to go through some examples of how people put together their mechanical models.'

'It helped me understand some of the content from the lectures better when seeing how it is applied to the real world.'

'Overall I liked the fact that we looked at research papers and saw what we are able to do with the knowledge gained from the lectures.'

Even more pronounced was the agreement to the statement that these assignments were more relevant by the students (45\% agreed and 39\% strongly agreed). The papers were chosen carefully with this as an important characteristic so it is not surprising but it is probably a major factor for the assignments being considered that motivating as well. Several comments suggest that the students do find the research papers inspiring for their project work:

'It was very good that research papers were recent and up to date and also quite closely related to our project task.'

I think especially for assignments the research-based tasks were a very nice alternation to traditional exercises. It felt more relevant and in my opinion more fun as well. I would not say that is was more difficult, it was just different. It may seem more complicated but in the actual tasks it was easier to understand what exactly I had to do.'

When asked what kind of assignments the students find best in terms of general learning outcome 39\% find the assignments based on authentic papers the better type, but $50 \%$ indicate that assignments based on traditional textbook problems are equally beneficial. $11 \%$ evaluate the outcome to be best by traditional exercises. In the essay answer several students suggest that a mix of the two types would be preferable, so it seems like a better strategy to regard the paper-based assignments as a useful alternative to traditional assignments.

On the other hand, the questionnaire revealed that it is not straight forward to introduce authentic research papers this early in an engineering program. Almost half the students $(45 \%)$ find these assignments more difficult than working with traditional textbook problems. Several student comments express that it is overwhelming to read a scientific paper. For some students it caused frustration while others found it boring to read. Also several students stated that it was harder to figure out what the actual task was and this influenced their motivation negatively. Clearly, there is a risk of imposing an early negative learning experience upon the students and it is important to try to avoid that since it might have huge negative influence on their education, especially for students with a pourer academic background [42]. Recommendations in this context are to give even more clear instructions, let 
the students work together and let them analyze each other's work [42].

Finally, the students did recognize that it was useful to try to read scientific papers even this early in a university program. They appreciated the glance into the scientist's laboratory and in fact a few students managed to give metacognitive reflections on the process:

I liked the idea that in the beginning we had to describe the purpose of the paper, because it takes some time to get into the topic and to know what they are doing and why. Later on in the last assignment - even though we did not have to do that task (to search for the purpose) - I started doing it, because it was so much easier.'

'I think that it is really helpful to see what task the researchers had in the beginning and what calculations they chose to consider. In our semester project we have to make calculations also, but often we do not know how to start. So I believe that having this kind of assignment is really relevant to the studies.'

\section{E. Limitations}

There is a range of limitations in this study appropriate to be mentioned. The small number of students in the sample is reducing the strength of data, even though the response rate was relatively high. The novelty of the pencasts may have produced a Hawthorne effect, which would have had an influence on the students' perception regarding these. On the contrary, this is assumed not to be the case for the voting tests using clickers, since this teaching style was used with the same cohort of students in the previous semester. The students assessing the efficiency of certain learning option is a very subjective measurement and in some cases it could be misleading. For instance, the students might feel that listening to the lecturer is efficient because they feel safe in that situation, where they are not challenged personally on their learning outcome. Some learning options may be efficient, but may also require a certain level of use. Hence, it is possible that students failed to acknowledge their efficiency, because they abandoned them early. It would be pertinent to include a comparison with the students' learning outcome directly, but it has not been considered within the scope of this work.

\section{CONCLUSIONS}

The aim of the study reported here was to present a teaching strategy for an engineering dynamics course based on several learning options and resources supporting different learning styles in a blended environment. The students' perception of the use and the efficiency of the different learning options offered were measured in order to optimize the strategy for future courses. In general, students were found to be positive to the blend, and they perceived the chosen elements to be effective regarding their learning outcome. Especially, the students value the variation in teaching style and indicate a positive influence in their motivation and engagement in the course topics.

It was found that pencasts, being an inexpensive and easy-to-adopt technology, can be a very fruitful tool and enhance the outcome and motivation when students are reading a traditional textbook. In addition, the pencasts were found to be useful to the students in their preparation for examination. The online lecture notes were considered efficient by the students too, and the students appreciated the close connection between the notes and the topics discussed at class.
The students found traditional lecturing very efficient, but it is stressed that in this context lecturing took up only a minor part of the time spent at class. Voting tests using clickers as a means to encourage peer discussion were implemented consequently at class, and the students rated the efficiency of such a teaching style high. A vast majority of students valued the alternation between the teachers lecturing, active learning through the voting tests and problem solving through class discussions.

In the present course setup the option of offering hints and answers to exercises and discussion boards on the course web-page were not used very much by the students. The efficiencies of these tools were relatively low, too. To increase these efficiencies it will be considered to create more interactive instruments for the future in order to meet the students' demands.

Finally, the study indicates that it is possible to include reading of authentic research papers very early in the bachelor program with a positive outcome. Many students found it interesting and motivating to see how real scientists use first year concepts and basic modelling in their professional work, even if the students do not understand everything in all detail. It is important to find papers which align closely not only to a theoretical course content but to other course work as well. Much care should be taken to establish a very clear framework for how the students are expected to work with an authentic paper to avoid frustration and a negative learning experience.

\section{ACKNOWLEDGMENT}

The author would like to thank the BHJ Foundation for financial support.

\section{REFERENCES}

[1] Schmidt, B., "Skip lecturing - Let the students talk!", Proceedings of the $12^{\text {th }}$ International Conference on Engineering and Technology Education (INTERTECH 2012), ed. by Claudio da Rocha Brito and Melany M. Ciampi, East Timor, 2012

[2] Kerres, M., de Witt, C., "A didactical framework for the design of blended learning arrangements", Journal of Educational Media, 28 (2-3), 2003, pp. 101-113 http://dx.doi.org/10.1080/ 1358165032000165653

[3] Moebs, S., Weibelzahl, S., "Towards a good mix in blended learning for small and medium sized enterprises - Outline of a Delphi Study", Proceedings of the Workshop on Blended Learning and SMEs, $1^{\text {st }}$ European Conference on Technology Enhanced Learning Crete, Greece, 2006

[4] Oliver, M. and Trigwel, K., "Can 'Blended Learning' be redeemed?”, E-learning, 2 (1), 2005, pp. 17-26 http://dx.doi.org/10.2304/elea.2005.2.1.2

[5] Peercy, P.S. and Cramer, S.M, "Redefining Quality in Engineering Education through Hybrid Instruction", Journal of Engineering Education, 100 (4), 2011, pp. 625-629 http://dx.doi.org/10.1002/ j.2168-9830.2011.tb00029.x

[6] Graham, C.R, Allen, S. and Ure, D., "Benefits and challenges of blended learning environments", Encyclopedia of Information Science and Technology, M. Khosrow-Pour, ed., Hershey, PA: Idea Group, 2005, pp. 263-259 http://dx.doi.org/10.4018/978-159140-553-5.ch047

[7] Cortizo, J.L., et al., "Blended learning applied to the study of mechanical couplings in engineering", Computers \& Education, 54 (4), 2010, pp. 1006-1019 http://dx.doi.org/10.1016/j.compedu. 2009.10.006

[8] Granic, A., Mifsud, C. and Cukusic, M., 2009. Design, implementation and validation of a Europe-wide pedagogical framework for e-learning. Computers \& Education, 53 (4), pp. 1052-1081 http://dx.doi.org/10.1016/j.compedu.2009.05.018 
[9] Felder, R.M. and Brent, R., "Understanding student differences", Journal of Engineering, 94 (1), 2005, pp. 57-72 http://dx.doi.org/10.1002/j.2168-9830.2005.tb00829.x

[10] Limniou, M. and Smith, M., “Teachers' and students' perspectives on teaching and learning through virtual learning environments", European Journal of Engineering Education, 35 (6), 2010, pp. 645-653 http://dx.doi.org/10.1080/03043797.2010.505279

[11] Dzakiria, H., Che, S.M. and Bakar, H.A., "Moving forward with blended learning as a pedagogical alternative to traditional classroom learning", Malaysian Online Journal of Instructional Technology, 3 (1), 2006, pp. 11-18

[12] Rogers, Y., Preece, J. and Sharp, H., Interaction design: Beyond human-computer interaction, New York: Wiley \& Sons, 2011

[13] Healey, M., "Linking research and teaching: Exploring disciplinary spaces and the role of inquiry based learning", I. R. Barnett (ed.): Reshaping the university. New relations between research, scholarship and teaching. Berkshire: Open University Press, 2005, pp. 67-78

[14] Osguthorpe, R.T. and Graham, C.R., "Blended learning environments: definitions and directions", The Quarterly Review of Distance Education, 4 (3), 2003, pp. 227-233

[15] Boyle, T., "A dynamic systematic method for developing blended learning", Education, Communication \& Information, 5 (3), 2005, pp. 221-232 http://dx.doi.org/10.1080/14636310500350422

[16] El-Zein, A., Langrish, T., Ballam, N., "Blended teaching and learning of computer programming skills in engineering curricula", Advances in Engineering Education, 1 (3), 2009, pp. 118

[17] Groen, L. and Carmody, G., "Blended learning in a first year mathematics subject", Proceedings of UniServe Science Blended Learning Symposium, 2005, pp. 50-55

[18] Wan Ahmed, W.F., Shafie, A., Janier, J.B., "Students' perceptions towards blended learning in teaching and learning mathematics: Application of integration", Proccedings of the $13^{\text {th }}$ Asian technology Conference in Mathematics, 2008

[19] Markvorsen, S. and Schmidt, K., "Online mathematics education e-math for first year engineering students", International Conference on Computer Supported Education (CSEDU 2012), Porto, Portugal, 2012

[20] Lux, J.R. and Davidson, B.D., "Guidelines for the development of computer-based instruction modules for science and engineering", Educational Technology \& Society, 6 (4), 2003, pp. 124-133

[21] Bourne, J., Harris, D. and Mayadas, F., "Online engineering education: learning anywhere, anytime", Journal of Engineering Education, 94 (1), 2005, pp. 131-146 http://dx.doi.org/10.1002/ j.2168-9830.2005.tb00834.x

[22] Martínez-Caro, E. and Campuzano-Bolarín, F., "Factors affecting students' satisfaction in engineering disciplines: traditional vs. blended approaches", European Journal of Engineering Education, 36 (5), 2011, pp. 473-483 http://dx.doi.org/10.1080/ 03043797.2011 .619647

[23] Mazur, E., Peer-Instruction: A user's manual, Upper Saddle River, NJ, Prentice Hall, 1997

[24] Fies, C. and Marshall, J., "Classroom response system: a review of the literature", Journal of Science Education and Technology, 15, 2006, pp. 101-109 http://dx.doi.org/10.1007/s10956-006-0360-1

[25] Nagy-Shadman, E. and Desrochers, C., "Student response technology: empirically grounded or just a gimmick?", International Journal of Science Education, 30 , 2008, pp. 20232066 http://dx.doi.org/10.1080/09500690701627253

[26] Fang, N., "Electronic classroom response system for an engineering dynamics course: student satisfaction and learning outcomes", International Journal of Engineering Education, 25 (5), 2009, pp. 1059-1067

[27] Schmidt, B., "Teaching engineering dynamics by use of peer instruction supported by an audience response system", European
Journal of Engineering Education, 36 (5), 2011, pp. 413-423 http://dx.doi.org/10.1080/03043797.2011.602185

[28] Marino, T.A., "Learning online: a view from both sides", The National Teaching \& Learning Forum, 9 (4), 2000, pp. 4-6

[29] Swales, J. M. and Feak, C. B., Academic writing for graduate students - essential tasks and skills. Ann Arbor: University of Michigan, 2004

[30] Jørgensen, P. S. and Rienecker, L., Studiehåndbogen - for studiestartere på videregående uddannelser. Frederiksberg: Samfundslitteratur, 2009

[31] Bean, J., "Teaching rhetorical reading of primary scientific literature to first year undergraduates: a two-stage writing assignment", Proceedings of EATAW Conference, Limerick, Ireland, 2011, pp. 100-101

[32] Jørgensen, A. H., "Kan diplomstuderende læse en peer-reviewed artikel i den første uge?" Dansk Universitetspaedagogisk Tidsskrift, 17, 2014, pp. 43-54

[33] Monk, A. M., Caroll, J., Parker, S. and Blythe, M., "Why are mobile phones annoying?", Behavior and Information Technology, 23 (1), 2004, pp. 33-41 http://dx.doi.org/10.1080/ 01449290310001638496

[34] Meriam, J.L. and Craige, L.G., Engineering Mechanics, Dynamics, 6.th ed., Hoboken, NJ: Wiley \& Sons, 2008

[35] Aydin, Y. O., Saranli, A., Yazicioglu, Y., Saranli, U. and Leblebicioglu, K., "Optimal control of half-circular compliant legged monopod”, Control Engineering Practice 33, 2014, pp. 10$21 \mathrm{http}: / / \mathrm{dx}$.doi.org/10.1016/j.conengprac.2014.08.005

[36] Zhu, J., Wang, Q. and Wang, L., "Effects of toe stiffness on ankle kinetics in a robotic transtibial prosthesis during level-ground walking”, Mechatronics 24, 2014, pp. 1254-1261 http://dx.doi.org/10.1016/j.mechatronics.2014.06.005

[37] Libby, T. et al., "Tail-assisted pitch control in lizards, robots and dinosaurs", Nature 481, 2012, pp. 181-184 http://dx.doi.org/10.1038/nature 10710

[38] Dysthe, O., "What is the purpose of feedback when revision is not expected? A case study of feedback quality and study design in a first year master's programme", Journal of Academic Writing, 1 (1), 2011, pp. 135-142 http://dx.doi.org/10.18552/joaw.v1i1.26

[39] Fitzpatrick, J., Cronin, K. and Byrne, E., "Is attending lectures still relevant in engineering education?", European Journal of Engineering Education, $36 \quad$ (3), 2010, pp. 301-312 http://dx.doi.org/10.1080/03043797.2011.585226

[40] Brodie, L.M., "eProblem-based learning: problem-based learning using virtual teams", European Journal of Engineering Education, 34 (6), 2009, pp. 497-509 http://dx.doi.org/10.1080/ 03043790902943868

[41] Madsen, M. L. and Winsløw, C., "Relations between teaching and research in physical geography and mathematics at researchintensive universities", International Journal of Science and Mathematical Education, (7) 2009, pp. 741-763

[42] Demirel, E., "Take it step by step: Following a process approach to academic writing to overcome student anxiety", Journal of Academic Writing, 1 (1), 2011, pp. 222-227 http://dx.doi.org/10.18552/joaw.v1i1.28

\section{AUTHOR}

B. Schmidt is with the Mads Clausen Institute, University of Southern Denmark, Alsion 2, 6400 Sonderborg, Denmark (e-mail: bschmidt@mci.sdu.dk).

This article is an extended and modified version of a paper presented at the 5th International Conference on Computer Supported Education (CSEDU 2015), 23-25 May 2015, Lisbon, Portugal. It has been financially supported by the BHJ Foundation. Submitted 06 August 2015. Published as resubmitted by the author 10 October 2015. 